\title{
Trade and the Neoclassical Growth Model*
}

\author{
Dan Ben-David \\ Tel Aviv University, NBER, and CEPR \\ Michael B. Loewy \\ University of South Florida
}

\begin{abstract}
The model developed in this paper expands upon the traditional neoclassical exogenous growth model by facilitating a long-run growth analysis of the impact of openness to trade within a multi-country framework. Openness affects growth by impacting the extent of knowledge spillovers from abroad. This feature effectively converts the traditional closed-economy exogenous growth model into a multi-country, open-economy endogenous growth model. Nevertheless, the conditional convergence and identical growth predictions of the neoclassical model are preserved here with the extent of trade now playing a role in determining the relative heights of the countries' parallel output paths.
\end{abstract}

- JEL Classifications: F43, O41

- Key words: Growth, Convergence, Trade liberatization

\section{Introduction}

As the world has become increasingly integrated during the postwar years, the debate on trade's impact on income growth and disparity has heated up. International organizations find their annual meetings the focus of strong public protests with the issue of "globalism" emerging front and center as a source of controversy

*Corresponding address: Professor Dan Ben-David, School of Government and Policy, Tel-Aviv University, Tel-Aviv, Israel, 69978; Tel: +972-3-740-9912; Fax: +972-3-640-7382; E-mail: danib@post.tau.ac.il Professor Michael Loewy, Department of Economics, University of South Florida, BSN3403, Tampa, FL 33620-5500, USA. Tel: 1-813-974-6532, Fax: +1-813-974-6510, E-mail: mloewy@ coba.usf.edu (C)2003-Center for International Economics, Sejong Institution, All Rights Reserved. 
between and within member countries. The questions raised by the various interest groups, international organizations, and governments center on whether increased openness is beneficial for all the countries involved - or whether the movement towards freer trade is part of a zero-sum game where any gains accrued by some countries come at the expense of others. ${ }^{1}$ As income gaps between some countries have narrowed during the postwar years while gaps between others have increased, the consequences of freer trade have not remained idle issues. The motivation underlying this paper is to provide a framework that can address these issues, a framework that focuses on the dynamic growth effects of trade liberalization.

The Solow (1956), Cass (1965) and Koopmans (1965) growth model has provided the primary framework for the examination of the growth process for the better part of the last half century. The model's growth and conditional convergence implications have withstood much of the surge in empirical growth-related research of the past decade. However, this framework describes a closed economy and the exogenous growth aspect of technological progress in the model does not facilitate an analysis of economic policy on steady-state growth.

A growing number of empirical studies point to a significant link between trade liberalization and growth as well as between trade liberalization and income convergence between countries (see, for example, Ben-David, 1993; Sachs and Warner, 1995). The objective here is to develop a theoretical framework that can account for this evidence by providing an open-economy modification of the traditional neoclassical growth model which includes an endogenous growth process that is affected by the extent of openness to trade.

The intuition here - as in Dollar, Wolff, and Baumol (1988), Rivera-Batiz and Romer (1991a, b), Grossman and Helpman (1991, 1995), and others - is that trade in goods serves as a conduit for knowledge flows between countries. ${ }^{2}$ These flows in turn serve to increase the productivity of capital and labor and hence the growth

\footnotetext{
${ }^{1}$ With regard to the general relationship between trade and income, Frankel and Romer (1999) conduct a natural experiment that examines the relationship between variations in the geographic component of trade and changes in income. They find that a rise of one percentage point in the ratio of trade to GDP increases income per capita by almost one-half percent and by more than one and one-half percent when a ratio of geographically-based trade to GDP is used.

${ }^{2}$ The trade conduit for knowledge flows has received empirical corroboration from several recent papers. These include Coe and Helpman (1995), Keller (1999), Lawrence and Weinstein (1999), Funk (2001a, b), and Lumenga-Neso, Olarreaga and Schiff (2001). Though the trade-growth relationship is the focus of this paper, this is not meant to suggest that trade is the only channel through which knowledge spillovers operate. Branstetter (2000), for example, highlights FDI's contribution in this regard.
} 
rate of per capita output. Since tariffs alter the flow of imports and therefore the flow of knowledge, it follows that trade liberalization can have an impact on the process of economic growth.

In contrast with most of the endogenous growth literature, the goal here is to maintain as close a relationship as possible to the original structure of the SolowCass-Koopmans model thereby preserving most of its important growth and conditional convergence predictions. Indeed, the model developed here collapses into the traditional model in the event that trade is prohibited. On the other hand, the open economy modification facilitates a multi-country analysis that goes beyond the two-country, two-region analysis that is common in much of the recent endogenous growth literature. ${ }^{3}$ Among other things, a multi-country model permits an analysis of the impact of trade liberalization on both steady-state growth rates and relative income levels of those countries involved in the movement towards free trade as well as those who do not participate in the liberalization process. ${ }^{4}$

Within the context of the model, technology grows at the same steady-state rate in each of the countries. However, the extent of protectionism that these countries impose determines their relative income levels, i.e., the height of their distinct growth paths. Trade liberalization, be it by one country or many, leads to faster global technological growth, which in turn causes every country to move to a steeper growth path. The liberalizing countries experience an increase in their income levels relative to those countries that do not liberalize trade and, in the case of a symmetric multilateral trade agreement, they converge with one another in per capita income. In other words, liberalization yields positive level effects for the countries that liberalize and produces positive growth effects for all countries. In addition, the model shows the effect of liberalization on domestic saving rates and offers some insight into the question posed by Lucas (1990) as to why capital does

\footnotetext{
${ }^{3}$ A notable exception is Ventura (1997) who analyzes a $J$-country world in which the common final good is non-traded while the two intermediate goods, which are produced with capital in one case and labor in the other, are both traded. Just as the model here can be viewed as either an endogenous or an exogenous growth model, so too can Ventura's. In his case, the distinction turns on the magnitude of the elasticity of substitution between the two intermediate inputs. If this value is greater than one, then the model exhibits endogenous growth and if it is less than one, then it exhibits growth only in the presence of exogenous technological progress.

${ }^{4}$ Ben-David and Loewy (2000) analyze a two-country model that shares many of the features found here. The emphasis in that paper is on proofs of existence and the impacts that arise from increased openness while the emphasis here is on developing the general multi-country version of the model and illustrating the non-zero-sum nature of increased participation in trade agreements. The technical issues that restrict Ben-David and Loewy (2000) to a two-country analysis limit that paper's ability to directly address the issues that are the primary focus here.
} 
not flow from rich to poor countries even though there exists an incentive for labor to immigrate to the wealthier countries.

In addition to modeling growth as endogenous, rather than an as exogenous, we also assume that tradable goods are produced in competitive final goods sectors rather than in monopolistically competitive intermediate goods sectors. Hence, to use the taxonomy of Chui et al. (2002), our model is one of "new growth and old trade." As Chui et al. point out, this particular combination of old or new growth with old or new trade has received far less attention in the literature than have the other three, although the work of Rivera-Batiz and Romer (1991a, b) and Findlay (1995, ch. 3) can usefully be construed as such. Hence, this paper offers a theory of the trade/growth link that is distinct from what is usually found in the literature. ${ }^{5}$

The next section of the paper provides a description of the model. Section III discusses the economy's steady state while Section IV provides some examples that illustrate the effects of trade liberalization. Section V concludes.

\section{The Model}

Consider a world with $J$ countries. Each country $i=1, \ldots, J$ is assumed to produce a distinct good which is also denoted as $i$. Let $n_{i}$ be the population growth rate in country $i$. Assume further that the population size and labor force within each country are equal to one another and that the initial population in each country, $L_{i}(0)$, is normalized to one. Next, let $c_{i j}(t)$ denote real per capita consumption of good $j$ in country $i$ at time $t$ and $p_{i}(t)$ denote the time $t$ price of good $i$ (with good 1 serving as the numéraire). To allow for the existence of bilateral trade between every pair of countries, let the utility function of the agents in country $i$ be given by

$$
\int_{0}^{\infty} e^{-\left(\rho_{i}-n_{i}\right) t} \sum_{j=1}^{J} \alpha_{i j} \ln c_{i j}(t) d t
$$

where $\sum_{j=1}^{J} \alpha_{i j}=1$ and $\rho_{i}$ is the rate of time preference.

In addition to $y_{i}(t)$, the per capita income (output) that they receive from selling good $i$, the agents of country $i$ also receive a per capita lump-sum transfer of

\footnotetext{
${ }^{5}$ As for the other three permutations, examples of these include Findlay $(1980,1984)$ and Burgstaller and Saavedra-Rivano (1984), old growth/old trade; Krugman (1979), Dollar (1986), Flam and Helpman (1987), and Baldwin and Seghezza (1996, 1998), old growth/new trade; and Grossman and Helpman (1991), Chui, Levine, and Pearlman (1999), Keller (2002), and Kind (2002), new growth/new trade.
} 
government tariff revenue, $g_{i}(t)$. This income is then used to finance the purchase of all $J$ goods and domestic investment. Let $k_{i}(t)$ denote per capita capital and $\tau_{i j}$ denote country $i$ 's tariff on imports from country $j$ (with $\tau_{i i}=0$ by definition). Assuming that the rate of capital depreciation is set equal to zero, it follows that country $i$ 's budget constraint is given by

$$
\sum_{j=1}^{J} \frac{p_{j}(t)}{p_{i}(t)}\left(1+\tau_{i j}\right) c_{i j}(t)+k_{i}(t)+n_{i} k_{i}(t) \leq y_{i}(t)+g_{i}(t)
$$

where

$$
g_{i}(t)=\sum_{j \neq 1} \frac{p_{j}(t)}{p_{i}(t)} \tau_{i j} c_{i j}(t)
$$

As in the traditional Solow-Cass-Koopmans model, output is a function of both physical capital and labor. In contrast with the traditional model, output growth here is assumed to result not only from capital accumulation and population growth, but also from the accumulation of knowledge over time. Hence, per capita output in country $i$ may be written as

$$
y_{i}(t)=k_{i}(t)^{\beta_{i}} H_{i}(t)^{\varepsilon_{i}}
$$

where $H_{i}(t)$ is the aggregate stock of knowledge in country $i$ at time $t, 0<\beta_{i}<1$ and $\varepsilon_{i}>0$. Thus, the model allows the intensities of capital and knowledge to differ across countries, although it does not require that they do so.

While some of the knowledge that $H_{i}$ represents might be specific to country $i$, there is also a component of $i$ 's knowledge stock that is general in nature and may be utilized by some, or all, of the other $J-1$ countries in the world. To simplify matters, we assume that knowledge is both non-rivalrous and to a certain extent non-excludable. Both the domestic stock of knowledge, $H_{i}$, and the foreign stocks of knowledge, $H_{j}$ for all $j \neq i$, play a role in determining the accumulation of domestic knowledge, $\dot{H}_{i}$. In the case of foreign knowledge stocks, however, the contribution of a particular $H_{j}$ towards the increase in $H_{i}$ depends upon two factors: (i) the extent to which country $i$ can access country $j$ 's knowledge and (ii) country $i$ 's ability to absorb and utilize the accessible part of country $j$ 's stock of knowledge.

Accessibility in the model is determined by the degree of openness between countries $i$ and $j$. Increased openness leads to both increased exposure to foreign ideas as well as to increased competitive pressures to assimilate all existing foreign knowledge in order to compete successfully with foreign firms at home as well as 
abroad. We assume, therefore, as do Grossman and Helpman (1991), that the share of country $j$ 's knowledge that country $i$ can access, what we define as $v_{i j}$, is an increasing function of the volume of trade between $i$ and $j$. To make things concrete, we define $v_{i j}$ as the endogenously determined ratio of country $i$ 's aggregate bilateral trade with country $j$ to country $i$ 's aggregate income, $v_{i j}(t)=$ $\left(I M_{i j}+E X_{i j}\right) / Y_{i}$, or more specifically:

$$
v_{i j}(t)=\frac{L_{i}(t) \frac{p_{j}(t)}{p_{i}(t)} c_{i j}(t)+L_{j}(t) c_{j t}(t)}{L_{i}(t) y_{i}(t)}
$$

Hence, $v_{i j} H_{j}$ represents the amount of country $j$ 's knowledge stock that is accessible to country $i$.

The extent of applicability, or usefulness, of country $j$ 's accessible knowledge stock towards the accumulation of knowledge in country $i$ is captured by the variable $a_{i j}$ and is assumed to depend in large part upon the similarity between $H_{j}$ and $H_{i}{ }^{6}$ To understand what is meant by "similarity", recall that the concept underlying the various $H_{i}$ 's is that they correspond to levels of knowledge that include both general and country-specific ideas. Hence, identical stocks of knowledge, namely $H_{j}=H_{i}$, do not necessarily imply that both countries possess identical sets of ideas, but rather that their individual levels of technology have progressed to comparable levels.

The more that $H_{j}$ exceeds $H_{i}$, the less conceivable it is that country $i$ will have the capability to absorb a large part of $j$ 's accessible knowledge stock. ${ }^{7}$ Hence, the contribution of $H_{j}$ to $\dot{H}_{i}$ will be minimal. Conversely, the more that $H_{i}$ exceeds $H_{j}$, once again the less will be the contribution of $H_{j}$ to $\dot{H}_{i}$, although for a different reason. Instead of a lack of capability on the part of country $i$, the issue here is the relevance of $H_{j}$ to $\dot{H}_{i}$ since the knowledge stock of country $j$ likely contains little that is germane to production in country $i .^{8}$

While the above discussion suggests that $a_{i j}$ is smaller the greater is the

\footnotetext{
${ }^{6}$ Keller (1999) provides empirical support for this assumption, showing that the extent of technology diffusion through trade depends on the extent that this trade is biased towards or away from technological leaders.

${ }^{7}$ As an example, advances in silicon chip technology in country $j$ will not be of much direct use to country $i$ when the latter has a largely illiterate population living in an agrarian-based economy that relies primarily upon oxen-towed plows (although these advances may have positive indirect effects on the economy through other channels).

${ }^{8}$ Continuing with the example from above, in this case advances in ox-based farming have little or no usefulness for most OECD economies.
} 
difference between $H_{i}$ and $H_{j}$, the question remains whether for given $H_{i}$ and $H_{j}$, $a_{i j}$ is either greater than or less than $a_{j i}$. Since one can reasonably argue that this inequality goes either way when $H_{i} \neq H_{j}$, we choose to be agnostic on this issue and assume that $a_{i j}=a_{j i}$ always. Thus, we define $a_{i j}(t)$ as

$$
a_{i j}(t)=A\left(\frac{H_{j}(t)}{H_{i}(t)}\right)= \begin{cases}\left(\frac{H_{j}(t)}{H_{i}(t)}\right)^{\mu} \text { if } & 0<\frac{H_{j}(t)}{H_{i}(t)} \leq 1 \\ \left(\frac{H_{j}(t)}{H_{i}(t)}\right)^{-\mu} \text { if } 1<\frac{H_{j}(t)}{H_{i}(t)} \leq \infty\end{cases}
$$

where $0<\mu<1$. Consequently, the closer is $H_{j}$ to $H_{i}$, the greater is the share of accessible $H_{j}$ that is useful for $i$ with $a_{i j}$ (and $a_{j i}$ ) rising to a maximum of one if and only if the two $H$ 's are equal. Putting the notions of accessibility and applicability together, it follows that the overall contribution of country $j$ 's knowledge to $\dot{H}_{i}$ is given by $a_{i j} v_{i j} H_{j}$.

To complete the description of country $i$ 's technology of knowledge accumulation, we assume as does Lucas (1988) that this technology is constant returns to scale. Therefore, we have that

$$
\dot{H}_{i}(t)=\phi_{i}\left[\sum_{j \neq 1} a_{i j}(t) v_{i j}(t) H_{j}(t)+H_{i}(t)\right]
$$

where $\phi_{i}>0$ is a country-specific productivity factor. Thus, the overall contribution of country $j$ 's knowledge towards the accumulation of knowledge in country $i$ is determined by the stock of knowledge in country $j$, the extent of trade openness between countries $i$ and $j$, and the extent of (dis)similarity between the stocks of knowledge of the two countries.

Note that in the absence of trade, $v_{i j}=0$ for all $i \neq j$. In such a case, (7) implies that the model reduces to the standard neoclassical growth model with technological progress accruing at the exogenous rate $\phi_{i}$. However, since agents' preferences imply that there will exist bilateral trade between all pairs of countries, it follows that $\phi_{i}$ provides a lower bound on the rate of knowledge accumulation in country $i$. Indeed, as is shown in the next section, the stocks of knowledge in all $J$ countries grow at the same rate in the steady state.

Having completed the set-up of the model, the emphasis now turns to an analysis of its steady state. In particular, the focus is on (i) the impact of trade liberalization on the growth of countries and (ii) the convergence (or lack thereof) between countries in the steady state. Inasmuch as tariffs do not explicitly appear 
in (4), it follows that these effects work through changes in relative prices which affect the quantities traded which in turn alter the $a v H$ terms that determine the common, steady-state rate of growth of knowledge.

\section{Equilibrium}

Suppose, as Lucas (1988) does, that private agents are atomistic. Within the present context, this implies that agents treat the time path of knowledge as beyond their influence. Consider then solving for what Lucas describes as the "equilibrium path". Let $z_{i}=y_{i} / k_{i}, \chi_{i}=c_{i i} / k_{i}$, and $\gamma_{x}=\dot{x} / x$ the growth rate of any variable $x$. Standard manipulations of the first-order conditions, Euler equation, budget constraint (2), and $J-1$ market clearing conditions,

$$
c_{i i}(t)+\sum_{j \neq i} \frac{L_{j}(t)}{L_{i}(t)} c_{j i}(t)+\dot{k}_{i}(t)+n_{i} k_{i}(t)=y_{i}(t), i=1, \ldots, J-1
$$

imply for each country $i=1, \ldots, J$ that in the steady state,

$$
\begin{gathered}
\gamma_{c_{i i}}^{*}=\beta_{i} z_{i}^{*}-\rho_{i} \\
\gamma_{k_{i}}^{*}=z_{i}^{*}-n_{i}-\frac{1}{\alpha_{i i}}\left[1-\sum_{j \neq i} \frac{\alpha_{i j} \tau_{i j}}{1+\tau_{i j}}\right] \chi_{i}^{*} \\
\gamma_{H_{i}}^{*}=\phi_{i}\left[\sum_{j \neq i} A\left(\frac{H_{j}^{*}}{H_{i}^{*}}\right) \times\left(\frac{\alpha_{j i} \pi_{j}\left(1-s_{i}^{*}\right)}{\alpha_{j j} \pi_{i}\left(1-s_{j}^{*}\right)} \frac{\chi_{j}^{*}}{z_{j}^{*}\left(1+\tau_{j i}\right)}+\frac{\alpha_{i j} \chi_{i}^{*}}{\alpha_{i i}^{*} z_{i}^{*}\left(1+\tau_{i j}\right)}\right) \times\left(\frac{H_{j}^{*}}{H_{i}^{*}}\right)+1\right],
\end{gathered}
$$

where $*$ denotes variables in the steady state, $s_{i}^{*}=\left(\gamma_{k_{i}}^{*}+n_{i}\right) / z_{i}^{*}$ is the steady-state saving rate in country $i$, and market clearing implies that the scalars $\pi_{i}$, for all $i=1, \ldots, J$, are functions of the preference parameters and tariff rates with $\pi_{1}=1$ by our choice of numéraire. ${ }^{9}$

By the definition of a steady state, the constant growth rates of consumption and capital imply from (9) and (10) that both $z_{i}$ and $\chi_{i}$ are constant in the steady state.

$$
\begin{aligned}
& \overline{{ }^{9} \text { For example, if } J=3, \pi_{2}}=\frac{\hat{\alpha}_{12}\left(\hat{\alpha}_{31}+\hat{\alpha}_{32}\right)+\hat{\alpha}_{13} \hat{\alpha}_{32}}{\hat{\alpha}_{21}\left(\hat{\alpha}_{31}+\hat{\alpha}_{32}\right)+\hat{\alpha}_{23} \hat{\alpha}_{31}} \text { and } \pi_{3}=\frac{\hat{\alpha}_{13}\left(\hat{\alpha}_{21}+\hat{\alpha}_{23}\right)+\hat{\alpha}_{12} \hat{\alpha}_{23}}{\hat{\alpha}_{21}\left(\hat{\alpha}_{31}+\hat{\alpha}_{32}\right)+\hat{\alpha}_{23} \hat{\alpha}_{31}} \\
& \text { where } \hat{\alpha}_{i j}=\frac{\alpha_{i j} Q_{i}}{1+\tau_{i j}} \text { and where and } Q_{i}=\frac{\prod_{j \neq i}\left(1+\tau_{i j}\right)}{1+\prod_{j \neq i} \tau_{i j}\left(1-\alpha_{i j}\right)+\alpha_{i i} \prod_{j \neq i} \tau_{i j}}
\end{aligned}
$$


It then follows from (11) that in order for the growth rate of knowledge in country $i$ to be constant, so too must be the $J-1$ relative stocks of knowledge. Consequently, the steady state will exhibit a common growth rate of knowledge for all countries. Hence, $c_{i i}, k_{i}$, and $y_{i}$ will all grow at the same rate and, from (4), this growth rate will be

$$
\gamma_{c_{i i}}^{*}=\gamma_{k_{i}}^{*}=\gamma_{y_{i}}^{*}=\frac{\varepsilon_{i}}{1-\beta_{i}} \gamma_{H}^{*}
$$

where $\gamma_{H}^{*}$ is the common steady-state rate of growth of knowledge. ${ }^{10}$

The economy's steady state is found by substituting the right-hand side of (12) for (i) $\gamma_{c_{i i}}^{*}$ in each of the $J$ versions of (9); (ii) $\gamma_{k_{i}}^{*}$ in each of the $J$ versions of (10), and (iii) $\gamma_{k_{i}}^{*}$ in the various $s_{i}^{*}$ terms in the $J$ versions of (11). These substitutions yield a system of $3 J$ equations in the $3 J$ unknowns $\left\{\gamma_{H}^{*}, z_{i}^{*}, \chi_{i}^{*}, H_{j}^{*} / H_{1}^{*}\right\}$, $i=1, \ldots, J ; j=2, \ldots, J$.

To provide some insight into the nature of the steady state, consider the $J \times J$ system described by (11). When all of the endogenous variables are equal to their steady-state values, it follows that $\gamma_{H_{i}}^{*}=\gamma_{H}^{*}$ corresponds to the maximum eigenvalue of the system and the ratios of knowledge stocks, $H_{j}^{*} / H_{i}^{*}$, correspond to the ratios of elements of the associated eigenvector. Inasmuch as the endogenous variables are themselves functions of this eigenvalue and eigenvector, it is seen that the steady state effectively corresponds to the solution of a particular fixedpoint problem.

In the steady state, the openness ratios, $v_{i j}^{*}$, are constants that are (in their implicitly-defined reduced forms) functions of, among other parameters, the tariff rates imposed by each of the countries. In particular, if countries are identical save for their initial conditions, then the presence of equal bilateral tariff rates within and across countries yields a single, common openness ratio and a common stock of knowledge. These in turn imply equal levels of per capita output. In other words, the Solow-Cass-Koopmans outcome of conditional convergence is replicated here although the term "conditional" is now based upon additional exogenous parameters such as tariff rates.

The primary area where this model differs from the traditional Solow-CassKoopmans model is in the endogeneity of steady-state growth. Unlike the traditional exogenous growth model in which there is no role for trade policy to

\footnotetext{
${ }^{10}$ To the extent that the production functions of any two countries differ in their intensities of capital and knowledge (i.e. $\beta_{i} \neq \beta_{j}$ and $\varepsilon_{i} \neq \varepsilon_{j}$ ), then these countries will exhibit distinct growth rates of output.
} 
affect growth, here commercial policies can, and do, affect steady-state growth. In the event that countries are identical and all bilateral tariffs are equal, then as noted above, $v_{i j}^{*}=v_{j i}^{*}=v^{*}$ and the common steady-state growth rate of knowledge is implicitly defined by

$$
\gamma_{H}^{*}=\phi\left[(J-1) v^{*}+1\right]
$$

Should all countries negotiate a common tariff reduction, then the resultant global liberalization will increase the common openness ratio, $v^{*}$, and, by (13), the outcome will be faster growth in the steady state.

What happens to growth rates and income levels when only one country liberalizes? How are other countries affected? More generally, how might a trade agreement whereby a subset of countries liberalizes trade among themselves and perhaps also undertakes unilateral tariff reductions towards some or all of the remaining countries affect the liberalizing countries, the non-liberalizing countries, and the relative income levels within and between the different groups? How do the outcomes from such a trade agreement differ from those of an agreement between all countries? These issues are addressed in the next section which provides a three-country simulation designed to show the steady-state effects of both two- and three--country trade agreements. Given that the steady state corresponds to finding the maximum eigenvalue of a $3 \times 3$ system, these effects can best be illustrated numerically.

\section{Examples}

To get a sense of the growth and level effects that result from trade liberalization, consider a three-country world in which the countries are identical in every respect save for their tariff policies and their initial levels of capital and knowledge. (The initial levels of capital and knowledge can each be any positive number since differences in these have no long-run consequences as far as the eventual steady-state growth paths are concerned.) In particular, assume that ( $\varepsilon, \beta$, $\phi, \rho, n, \mu)=(0.3,0.4,0.05,0.04,0.02,0.5), \alpha_{i j}=0.333$ for $i, j=1,2,3, \tau_{12}=\tau_{13}$ $=0.2, \tau_{21}=\tau_{23}=0.4$, and $\tau_{31}=\tau_{32}=0.6$. The unique pre-liberalization steady state is given in the second column of Table 1 . Country 1, with the lowest tariffs, ends up on the highest growth path (as evidenced by $y_{1}^{*} / y_{3}^{*}>y_{1}^{*} / y_{2}^{*}>1$ ) while the other countries are on parallel, albeit lower, growth paths. In particular, country 3 , the country with the highest tariffs, is also the poorest. Thus, the level effects present 
in the steady state are consistent with Mourmouras (1991), Easterly and Rebelo (1993), Polley (2000), Tanzi and Zee (2000) and others who show that developing countries tend to tax trade more than do developed countries.

In contrast with the neoclassical growth model, differences in per capita income between the three countries occur in the steady state despite the countries having identical saving rates, $s^{*}$, and identical marginal products of capital, $\beta z^{*}$. This result provides one answer to the question that Lucas (1990) posed, namely, why is there a paucity of capital flows from rich countries to poor ones. Given the equality of marginal products across countries, there is no incentive for such capital flows to arise.

Suppose that a free-trade agreement between the two wealthier countries is signed whereby both the top- and middle-income countries (1 and 2) eliminate

Table 1. Trade Liberalization in a Three-Country World

\begin{tabular}{|c|c|c|c|}
\hline Variable & $\begin{array}{c}\text { Pre-liberalization } \\
\text { steady state } \\
\begin{array}{c}\tau_{12}=\tau_{13}=0.2 \\
\tau_{21}=\tau_{23}=0.4 \\
\tau_{31}=\tau_{32}=0.6\end{array}\end{array}$ & $\begin{array}{l}\text { Two-country free- trade } \\
\text { agreement steady state } \\
\begin{aligned} \tau_{12}=\tau_{21}=0.0 \\
\tau_{21}=\tau_{23}=0.2 \\
\tau_{31}=\tau_{32}=0.6\end{aligned}\end{array}$ & $\begin{array}{l}\text { Three-country free-trade } \\
\text { agreement steady state } \\
\begin{aligned} \tau_{12}=\tau_{21}=0.0 \\
\tau_{21}=\tau_{23}=0.0 \\
\tau_{31}=\tau_{32}=0.0\end{aligned}\end{array}$ \\
\hline$\gamma_{H}^{*}$ & $8.98 \%$ & $9.12 \%$ & $9.61 \%$ \\
\hline$\gamma_{y}^{*}$ & $4.49 \%$ & $4.56 \%$ & $4.81 \%$ \\
\hline$y_{1}^{*} / y_{2}^{*}=k_{1}^{*} / k_{2}^{*}$ & 1.0174 & 1.0000 & 1.0000 \\
\hline$y_{1}^{*} / y_{3}^{*}=k_{1}^{*} / k_{3}^{*}$ & 1.0413 & 1.0698 & 1.0000 \\
\hline$y_{2}^{*} / y_{3}^{*}=k_{3}^{*} / k_{3}^{*}$ & 1.0235 & 1.0698 & 1.0000 \\
\hline$a_{12}^{*} v_{12}^{*}$ & 0.4265 & 0.4895 & 0.4606 \\
\hline$a_{13}^{*} v_{13}^{*}$ & 0.4167 & 0.3816 & 0.4606 \\
\hline$a_{21}^{*} v_{21}^{*}$ & 0.4014 & 0.4895 & 0.4606 \\
\hline$a_{23}^{*} v_{23}^{*}$ & 0.3990 & 0.3816 & 0.4606 \\
\hline$a_{31}^{*} v_{31}^{*}$ & 0.3704 & 0.3604 & 0.4606 \\
\hline$a_{32}^{*} v_{32}^{*}$ & 0.3768 & 0.3604 & 0.4606 \\
\hline$s^{*}$ & 0.3058 & 0.3065 & 0.3091 \\
\hline$z^{*}$ & 0.2123 & 0.2140 & 0.2201 \\
\hline$\beta z^{*}$ & 0.0849 & 0.0856 & 0.0880 \\
\hline
\end{tabular}

The parameter vector satisfies $(\varepsilon, \beta, \phi, \rho, n, \mu)=.(10.3,0.4,0.05,0.04,0.02,0.5)$ 
tariffs on trade with each other and move to a common external tariff towards country 3 . Specifically, let $\tau_{12}$ and $\tau_{21}$ fall to 0 while $\tau_{13}=\tau_{23}=0.2$ with all other parameters being unchanged. The associated changes in relative prices affect the steady-state levels of the shares of foreign knowledge that contribute to the accumulation of knowledge in country $i$, the $a_{i j} v_{i j}$ 's, with some rising and others falling. Since the steady-state rate of growth of knowledge is a function of all six of the $a_{i j} v_{i j}$ 's, the impact on rates of growth of per capita output from such a trade agreement is not a priori obvious.

The two-country free-trade agreement steady state is given in the third column of Table 1. The tariff reductions of Countries 1 and 2 increase the common steadystate rates of growth of knowledge and per capita output, $\gamma_{H}^{*}$ and $\gamma_{y}^{*}$, the average and marginal products of capital, $z^{*}$ and $\beta z^{*}$, and the saving rate, $s^{*}$. By equating their internal and external tariffs, Countries 1 and 2 also converge to a common growth path while at the same time widening their income gaps with Country 3 $\left(y_{1}^{*} / y_{3}^{*}=y_{2}^{*} / y_{3}^{*}=1.0698\right.$ versus 1.0413 and 1.0235 previously). Country 3 nevertheless benefits from the agreement by the other two countries inasmuch as now it too grows at the higher common rate, $\gamma_{y}^{*}=4.56 \%$, as compar-ed to $4.49 \%$ prior to liberalization.

How well do these outcomes from the model compare with the empirical evidence? Within the model, a trade agreement between the top two countries that coincides with the imposition of equal external tariffs by both countries on the third leads to an outcome of faster growth for all three countries. Empirically, an agreement such as this resembles the implementation of the Treaties of Rome that created the European Economic Community in the late 1950s and the model's growth results are consistent with the long-run increases in growth rates for these countries reported by Maddison (1982) and Ben-David and Papell (1995). The faster growth by all is accompanied by income convergence among the top two countries (as occurred within the EEC) and a persistent gap between the two leaders and the third country. The latter outcome, that of non-convergence, or even of divergence between the leading countries and those that are less developed, is one of the empirical regularities that has characterized the postwar world. ${ }^{11}$

Finally, what happens if all three countries sign a free-trade agreement that eliminates tariffs on all trade between them? As the right-hand column in Table 1

\footnotetext{
${ }^{11}$ For examples of countries where liberalization brings about income convergence and increased growth, see Ben-David (1993) and Sachs and Warner (1995). For evidence of non-convergence between developed and less developed countries, see Baumol (1986) and Ben-David (1995).
} 
indicates, the outcome is income convergence between all three countries (as evidenced by $y_{1}^{*} / y_{2}^{*}=y_{1}^{*} / y_{3}^{*}=y_{2}^{*} / y_{3}^{*}=1$ ) accompanied by even faster output growth in the steady state than in the two-country agreement case, $4.81 \%$ versus $4.56 \%$. This growth rate is nearly twice that found in autarky, namely $2.5 \%$.

\section{Conclusion}

This paper considers an open-economy modification of the neoclassical growth model that makes the growth process endogenous and allows for the presence of both level and growth effects to arise from trade liberalization. The model, which adds knowledge as an input to production along with capital and labor, replicates the behavior of the neoclassical model with exogenous technological progress when trade is prohibited. When trade is permitted, the model implies that in addition to the expected level effects, liberalization also brings about a shared growth effect; all countries grow faster in the steady state.

As in the standard neoclassical growth model, the model developed here implies that in a steady state there will be conditional convergence among countries that equalize their tariffs both internally and externally. Moreover, these countries will open up an income gap relative to those higher tariff countries that do not participate in the agreement. Despite these differences in income levels in the steady state, all countries will nevertheless exhibit the same saving rates and marginal products of capital.

Assuming comparable technologies, the model also retains the standard neoclassical growth model's implication that all countries grow at the same rate in the steady state. This in turn implies that those countries maintaining high trade taxes will not see their incomes converge to those with low trade taxes unless and until they lower their taxes as well. Furthermore, tariff reductions increase trade which in turn increase the common steady-state growth rate of knowledge accumulation in all countries as well as the common steady-state saving rates and marginal products of capital. Consequently, all countries grow faster following the implementation or expansion of trade agreements.

As additional countries liberalize trade, growth rates increase further. In sum, the model expands upon the traditional neoclassical growth model by facilitating multi-country, long-run analyses in which the extent of trade liberalization can affect the endogenously determined rate of steady-state growth. 


\section{Acknowledgement}

We thank seminar participants at the 2000 Midwest Macroeconomics Conference, the 2000 Meetings of the Society for Economic Dynamics, and the University of Central Florida for their suggestions. The second author acknowledges that this work was supported, in part, by the University of South Florida Research and Creative Scholarship Grant Program under Grant No. 1403933RO.

Received July 2002, Accepted November 2002

\section{References}

Baldwin, R.E. and E. Seghezza (1998), Regional Integration and Growth in Developing Nations. Journal of Economic Integration 13(3), 367-99.

Baldwin, R.E. and E. Seghezza (1996), Trade-Induced Investment-Led Growth. NBER Working Paper 5582. NBER, Cambridge, MA.

Baumol, W.J. (1986), Productivity Growth, Convergence, and Welfare: What the LongRun Data Show. American Economic Review 76(5), 1072-85.

Ben-David, D. (1995), Convergence Clubs and Diverging Economies, Foerder Institute Working Paper 40-95. Tel Aviv University.

Ben-David, D. (1993), Equalizing Exchange: Trade Liberalization and Income Convergence. Quarterly Journal of Economics 108(3), 653-79.

Ben-David, D., and M.B. Loewy (2000), Knowledge Dissemination, Capital Accumulation, Trade, and Endogenous Growth. Oxford Economic Papers 52(4), 63750.

Ben-David, D., and D.H. Papell (1995), The Great Wars, the Great Crash, and Steady State Growth: Some New Evidence about an Old Stylized Fact. Journal of Monetary Economics 36(3), 453-75.

Branstetter, L., (2000), Is Foreign Direct Investment a Channel of Knowledge Spillovers ? Evidence from Japan's FDI in the United States. NBER Working Paper 8015. NBER, Cambridge, MA.

Burgstaller, A. and N. Saavedra-Rivano (1984), Capital Mobility and Growth in a NorthSouth Model. Journal of Development Economics 15(1-2-3), 213-37.

Cass, D. (1965), Optimum Growth in an Aggregate Model of Capital Accumulation. Review of Economic Studies 32(3), 233-40.

Chui, M., P. Levine, and J. Pearlman (1999), Does the South Benefit from Free Trade? Trade Policy in a New Growth, New Trade North-South Model. Mimeo.

Chui, M., P. Levine, S.M. Murshed, and J. Pearlman (2002), North-South Models of Growth and Trade. Journal of Economic Surveys 16(2), 123-65. 
Coe, D., and E. Helpman (1995), International R\&D Spillovers. European Economic Review 39(5), 859-87.

Dollar, D. (1986), Technological Innovation, Capital Mobility, and the Product Cycle in North-South Trade. American Economic Review 76(1), 177-90.

Dollar, D., E.N. Wolff, and W.J. Baumol (1988), The Factor-Price Equalization Model and Industry Labor Productivity: An Empirical Test across Countries. In: R. C. Feenstra (ed.), Empirical Methods for International Trade. Cambridge, MA: MIT Press, 23-47.

Easterly, W., and S. Rebelo (1993), Fiscal Policy and Economic Growth: An Empirical Investigation. Journal of Monetary Economics 32(3), 417-58.

Findlay, R. (1995), Factor Proportions, Trade, and Growth. Cambridge, MA: MIT Press.

Findlay, R. (1984), Growth and Development in Trade Models. In R.W. Jones and P.B. Kenen (eds.), Handbook of International Economics, Vol. 1. Amsterdam: NorthHolland, 185-236.

Findlay, R. (1980), The Terms of Trade and Equilibrium Growth in the World Economy. American Economic Review 70(3), 291-99.

Flam, H. and E. Helpman. (1987), Vertical Product Differentiation and North-South Trade. American Economic Review 77(5), 810-22.

Frankel, J.A., and D. Romer (1999), Does Trade Cause Growth? American Economic Review 89(3), 379-99.

Funk, M.F. (2001a), International R\&D Spillovers and Convergence among OECD Countries. Journal of Economic Integration 16(1), 48-65.

Funk, M.F. (2001b), Trade and International R\&D Spillovers among OECD Countries. Southern Economic Journal 67(3), 725-36.

Grossman, G.M., and E. Helpman (1995), Technology and Trade. In G. Grossman and K. Rogoff (eds.), Handbook of International Economics, Vol. 3. Amsterdam: NorthHolland, 1279-337.

Grossman, G.M., and E. Helpman (1991), Innovation and Growth in the Global Economy. Cambridge, MA: MIT Press.

Keller. W. (2002), Trade and the Transmission of Technology. Journal of Economic Growth 7(1), 5-24.

Keller, W. (1999), How Trade Patterns and Technology Flows affect Productivity Growth. NBER Working Paper 6990. NBER, Cambridge, MA.

Kind, H.J. (2002), Endogenous Growth and Trade Liberalization between Small and Large Countries. Review of International Economics 10(1), 151-65.

Koopmans, T.C. (1965), On the Concept of Optimal Economic Growth. In Pontificia Academia Scientiarum, The Econometric Approach to Development Planning. Amsterdam: North-Holland.

Krugman, P.R. (1979), Increasing Returns, Monopolistic Competition and International Trade. Journal of International Economics 9(4), 469-79.

Lawrence, R.Z., and D.E. Weinstein (1999), Trade and Growth: Import-led or Export-led? Evidence from Japan and Korea. NBER Working Paper 7264. NBER, Cambridge, MA. 
Lucas, R.E., Jr. (1990), Why Doesn't Capital Flow from Rich to Poor Countries? American Economic Review Papers and Proceedings 80(2), 92-96.

Lucas, R.E., Jr. (1988), On the Mechanics of Economic Development. Journal of Monetary Economics 22(1), 3-42.

Lumenga-Neso, O., M. Olarreaga, and M. Schiff (2001), On "Indirect" Trade-Related R\&D Spillovers. World Bank working paper. World Bank, Washington, DC.

Maddison, A. (1982), Phases of Capitalist Development. Oxford: Oxford University Press.

Mourmouras, A. (1991), Infant Governments and the Fiscal Role of Tariffs, Inflation, and Reserve Requirements. Journal of International Economics 31(3-4), 271-90.

Polley, W. (2000), Costly Auditing and the Revenue Function of Tariffs. Working Paper, Bradley University.

Rivera-Batiz, L.A., and P.M. Romer (1991a), International Trade with Endogenous Technological Change. European Economic Review 35(4), 971-1004.

Rivera-Batiz, L.A., and P.M. Romer (1991b), Economic Integration and Endogenous Growth. Quarterly Journal of Economics 106(2), 531-55.

Sachs, J.D., and A. Warner (1995), Economic Reform and the Process of Global Integration. Brookings Papers on Economic Activity (1), 1-95.

Solow, R.M. (1956), A Contribution to the Theory of Economic Growth. Quarterly Journal of Economics 70(1), 65-94.

Tanzi, V. and H.H. Zee (2000), Tax Policy for Emerging Markets: Developing Countries. National Tax Journal 53(2), 299-322.

Ventura, J. (1997), Growth and Interdependence, Quarterly Journal of Economics 112(1), 57-84. 